\title{
Ralstonia pickettii Enhance the DDT Biodegradation by Pleurotus eryngiis
}

\author{
Adi Setyo Purnomo ${ }^{1 *}$, Diana Maulianawati ${ }^{2}$, and Ichiro Kamei ${ }^{3}$ \\ ${ }^{1}$ Department of Chemistry, Faculty of Science, Institut Teknologi Sepuluh Nopember (ITS), Kampus ITS Sukolilo, Surabaya 60111, Indonesia \\ ${ }^{2}$ Department of Aquaculture, Faculty of Fisheries and Marine Science, Borneo Tarakan University, Amal Lama No. 01, Tarakan Timur, \\ Tarakan, 77123, Indonesia \\ ${ }^{3}$ Department of Forest and Environmental Science, Faculty of Agriculture, University of Miyazaki, 1-1, Gakuen-kibanadai-nishi, Miyazaki \\ 889-2192, Japan
}

\author{
Received: June 14, 2019 \\ Revised: August 23, 2019 \\ Accepted: August 28, 2019 \\ First published online \\ September 2, 2019 \\ *Corresponding author \\ Phone: +62-31-5943353 \\ Fax: +62-31-5928314 \\ E-mail: adi_setyo@chem.its.ac.id
}

$S$ upplementary data for this paper are available on-line only at http://jmb.or.kr.

pISSN 1017-7825, eISSN 1738-8872

Copyright@ 2019 by

The Korean Society for Microbiology and Biotechnology

\begin{abstract}
DDT is a hydrophobic organic pollutant, which can be bio-accumulated in nature and have adverse consequences on the physical condition of humans and animals. This study investigated the relationship between the white-rot fungus Pleurotus eryngii and biosurfactantproducing bacterium Ralstonia pickettii associated with the degradation of DDT. The effects of R. pickettii on fungal development were examined using in vitro confrontation assay on a potato dextrose agar (PDA) medium. $R$. pickettii culture was added to the $P$. eryngii culture at $1,3,5,7$, and $10 \mathrm{ml}\left(1 \mathrm{ml} \approx 1.44 \times 10^{13} \mathrm{CFU}\right)$. After $7 \mathrm{~d}$ incubation, about $43 \%$ of the initial DDT $(12.5 \mu \mathrm{M})$ was degraded by the $P$. eryngii culture only. The augmentation of $7 \mathrm{ml}$ of $R$. pickettii culture revealed a more highly optimized synergism with DDT degradation being approximately $78 \%$ and the ratio of optimization 1.06. According to the confrontational assay, $R$. pickettii promoted the growth of $P$. eryngii towards the bacterial colony, with no direct contact between the bacterial cells and mycelium $(0.71 \mathrm{~cm} /$ day). DDD (1,1-dichloro-2,2-bis(4chlorophenyl) ethane), DDE (1,1-dichloro-2,2-bis(4-chlorophenyl) ethylene), and DDMU (1chloro-2,2-bis(4-chlorophenyl) ethylene) were identified as metabolic products, indicating that the $R$. pickettii could enhance the DDT biodegradation by P. eryngii.
\end{abstract}

Keywords: Biodegradation, DDT, bacteria, white-rot fungi, Pleurotus eryngii, Ralstonia pickettii

\section{Introduction}

Although 1,1,1-trichloro-2,2-bis(4-chlorophenyl) ethane (DDT) was tagged illegal in 1974, it has recently been observed in high concentrations in water, soils, and sediments of agricultural regions. The massive use of DDT in 1974-1982 caused high levels of residues of this substance to be detected in fish and mussels [1]. Furthermore, in Africa, DDT is widely used for the control of malaria as it is cheaper and more effective than other pesticides [2]. Tsakiris et al. [3] reported that $97.4 \%$ of the milk samples in Greece contained DDT residues. The EPA has classified DDT as a B2 carcinogen, meaning that people exposed to DDT had higher risks of cancer and endocrine disruption. Because it has a way of accumulating in animals, with those lower in the food chain eaten by their superiors, DDT becomes highly concentrated in tissues of predators [3]. This continues up to the point when the top predator receives the highest dosage, which in turn leads to negative health challenges. Hence, the contamination with DDT of soil, ground water, surface water, and sediment is as an important environmental concern worldwide.

Several techniques for the removal of DDT and its metabolites exist, including physical-chemical methods [46]. Even though these removal methods are very effective, they are often very costly. Thus, biodegradation is often the safest and most efficient method for removing numerous organic pollutants, including DDT, since it uses microorganisms as agents that degrade DDT by changing the structure of the compound which always occurs when 
electrons are lost or gained. This will change the properties of DDT into less or nontoxic metabolites. Both bacteria and fungi are famous in degrading or deteriorating an expansive discord of compounds and materials. Extracellular ligninolytic enzymes consisting of lignin peroxidase (LiP), laccase, and manganese peroxidase $(\mathrm{MnP})$ are primary factors of a lignin-degrading enzyme system and white-rot fungi (WRF). It has the ability to weaken environmental contaminants such as polychlorinated dioxins [7], polychlorinated biphenyls [8], cyclodiene insecticide [9], industrial dye effluents, munitions waste, pesticides, herbicides, and petroleum hydrocarbons [10-13]. Some of the WRF that possess the capability to degrade DDT include Phanerochaete chrysosporium, Trametes versicolor [14], Pleurotus ostreatus [15-17], Pleurotus florida, Pleurotus sajorcaju, Pleurotus eryngii [18], Phlebia lindtneri and Phlebia brevispora [19, 20], and Ganoderma lingzhi [21] as well as some brown-rot fungi [22-24]. Besides, Arisoy [18] also reported that $P$. eryngii could degrade DDT approximately $66 \%$ over a 20 -day incubation period in mineral medium. However, this research had not reported the metabolites produced from the DDT degradation by P. eryngii and the amount of degradation rate was still low. Therefore, modification of the culture to enhance the ability of $P$. eryngii to degrade DDT was needed.

The association of bacteria with fungi has been investigated since the 1960s by a small number of researchers. Bacteria decompose woody materials, with a good number of them developing into synergistic relationships with fungi [25]. According to Clausen [26], some bacterial metabolic commodities operate as growth enhancers for fungi, while nitrogen-fixing bacteria provide nitrogen in an environment with a low nitrogen/carbon ratio. Hence, this association might be useful in improving the biodegradation of recalcitrant pollutants using wood-rotting fungi. The study, therefore, aims at investigating the dynamic relationship between the WRF P.eryngiii and the biosurfactantproducing bacterium Ralstonia pickettii associated with the degradation of DDT. Lipase from $R$. pickettii has also proven to be a capable additive that improves the removal of oil from cotton fabrics [27]. R. pickettii could also degrade some organic pollutants such as benzene, meta-cresol [2729], ortho-cresol, para-cresol [30], pentachlorophenol [31], nitrobenzene [32], pentacyclic triterpenoids [33], and toluene [34]. In previous works, R. pickettii was reported to possess the capability to degrade DDT in potato dextrose broth (PDB) medium and could effectively enhance DDT degradation by brown-rot fungus Daedalea dickinsii in a mixed-culture treatment [35]. Thus, the effect of the addition of R. pickettii in the biodegradation of DDT by $P$. eryngii and fungal growth was examined along with the identification of its degradation pathway and metabolic products.

\section{Materials and Methods}

\section{Materials}

Pleurotus eryngii NBRC 32798, and Ralstonia pickettii NBRC 102503 were provided by the Laboratory of Microbial Chemistry, Institut Teknologi Sepuluh Nopember, Surabaya, Indonesia. DDT, DDE (1,1-dichloro-2,2-bis(4-chlorophenyl) ethylene), DDD (1,1dichloro-2,2-bis(4-chlorophenyl) ethane), DDMU (1-chloro-2,2bis(4-chlorophenyl) ethylene), and pyrene were acquired from Tokyo Chemical Industry Co. (Japan). Dimethylsulfoxide (DMSO), methanol, and sodium sulfate anhydrous were obtained from Merck, Millipore (Germany). Acetone and $n$-hexane were acquired from Anhui Fulltime Specialized Solvent and Reagent Co., Ltd. (China).

\section{Preparation of Fungus Culture}

The $P$. eryngii culture was maintained on a 9-cm diameter of PDA plates (Difco, UK) that had been incubated at $30^{\circ} \mathrm{C}$. Mycelium $(1-\mathrm{cm}$ diameter) were transferred into PDB (Difco) medium in a 100-ml Erlenmeyer flask $(10 \mathrm{ml})$. The cultures were also pre-incubated for 7 days at $30^{\circ} \mathrm{C}[36-38]$

\section{DDT Biodegradation by $P$. eryngii}

After the 7-day pre-incubation process, $50 \mu \mathrm{l}$ of DDT $5 \mathrm{mM}$ (final concentration of $12.5 \mu \mathrm{M}$ /flask) was added to each P. eryngiiinoculated flask. Furthermore, the oxygen was exhilarated into each flask and secured with a glass stopper to prevent the substrate from volatilization. As a control, the cultures were incubated at $30^{\circ} \mathrm{C}$ for 7 days and killed using an autoclave $\left(121^{\circ} \mathrm{C}\right.$, $20 \mathrm{~min}$ ) after the pre-incubation process. Experiments on DDT biodegradation were conducted in triplicates. The average of the three values presents the data $[39,40]$.

\section{Bacteria Culture Conditions}

The $R$. pickettii culture was maintained on a nutrient agar (NA, Difco) incubated at $37^{\circ} \mathrm{C}$ and transferred into $100-\mathrm{ml}$ Erlenmeyer flasks containing $50 \mathrm{ml}$ nutrient broth (NB, Difco, UK). The cultures were also pre-incubated for $30 \mathrm{~h}$ at $37^{\circ} \mathrm{C}$ with shaker $(11 \times g)[41,42]$

\section{Biodegradation of DDT by $P$. eryngii with the Addition of Bacteria}

After pre-incubating the WRF P. eryngii for 7 days, R. pickettii culture was separately added in different concentrations of $1,3,5$, 7 , and $10 \mathrm{ml}\left(1.44 \times 10^{13} \mathrm{CFU} / \mathrm{ml}\right)$. In each inoculated flask, $50 \mu \mathrm{l}$ 
of DDT $5 \mathrm{mM}$ (final concentration of $12.5 \mu \mathrm{M}$ /flask) was added and flushed with oxygen, to prohibit the volatilization of the substrate, and the flask was sealed with a glass stopper. As a control, an autoclave was used to kill the cultures at $121^{\circ} \mathrm{C}$, for $20 \mathrm{~min}$. Furthermore, all experiments were conducted in triplicates, with the optimization ratio calculated by number of degradation by mixed cultures per total amount of degradation by fungus and bacteria $[43,44]$.

\section{Determination of DDT and Its Metabolites}

After incubation for 7 days, $50 \mu \mathrm{l}$ of pyrene $(5 \mathrm{mM})$ in DMSO were added to the cultures, which was then washed with $20 \mathrm{ml}$ methanol and $5 \mathrm{ml}$ acetone. To remove the biomass, the mixtures were homogenized, centrifuged at 3,024 $\times g$ for $10 \mathrm{~min}$ and filtered through a glass fiber filter with the filtrates mixed and evaporated. The filtrates were extracted using $200 \mathrm{ml} n$-hexane in order to collect the organic fractions. Furthermore, they were passed through anhydrous sodium sulfate and merged. The extracts were then concentrated by an evaporator. Next, they were diluted with methanol and analyzed by HPLC (Jasco, Japan) to estimate the concentration of DDT. Methanol at a percentage of $82 \%$ in $0.1 \%$ trifluoroacetic acid aqueous solution was eluted at a flow rate of $1 \mathrm{ml} / \mathrm{min}^{-1}$. Furthermore, DDT and its metabolic products were recognized on the basis of the retention time and maximally absorbed at specific wavelengths compared to authentic standards. For quantitative analysis, the peak areas and metabolites were compared with pyrene [24]. To classify the metabolic products that were not detected by the HPLC, samples were also diluted with $n$-hexane and analyzed using GC/MS (Agilent 7890A). The temperature, was at $80^{\circ} \mathrm{C}$ for $3 \mathrm{~min}$, preceded by a linear increase to $320^{\circ} \mathrm{C}$ at $12^{\circ} \mathrm{C} \mathrm{min}^{-1}$ and held at $300^{\circ} \mathrm{C}$ for $5 \mathrm{~min}[17,45]$.

\section{Confrontational Assay}

After pre-incubation, $20 \mathrm{ml}$ of bacteria cultures were centrifuged (10 min at 3,024 $\times g$ ) and the filtrate was removed. About $20 \mathrm{ml}$ of sterile purified water was added, and the samples were then homogenized and centrifuged (10 $\mathrm{min}$ at 3,024 $\times g$ ), the filtrate was removed, and the process was repeated thrice. Bacterial cells were transferred into the PDA plates. They were then placed at a distance of $4 \mathrm{~cm}$ from the fungal disk, which was incubated at $25^{\circ} \mathrm{C}$ for 10 days in the dark. From the 4 th day, the mycelial growth was measured and evaluated $[25,46]$.

\section{Statistical Analysis}

All measurements and treatments were administered in triplicate with results expressed in mean values and standard deviation (SD). An Excel spreadsheet was used to calculate data, while the Student's $t$-test was carried out to analyze the significant differences between the various treatments using SPSS 22 for Windows (SPSS Inc., USA). The means were estimated at a significance level of $5 \%(p<0.05)$.

\section{Results}

A fungal-bacterial confrontation assay was conducted to determine the interaction between $P$. eryngii and $R$. pickettii. Fig. 1 showed the P. eryngii mycelium growth after 12 days of incubation. The morphology of $P$. eryngii changed, and was marked by a change in the color of the mycelium with the bacterial colony in partial contact on one side of the plate $(1 b, 1 c)$. The color of the mycelium tends to be yellowish and denser (1c, black arrows) compared to the mycelium without bacterium (1a). P. eryngii mycelium which was directly confronted with $R$. pickettii, showed twice the growth $(0.71 \pm 0.08 \mathrm{~cm} /$ day $)$ than the control $(0.38 \pm 0.04 \mathrm{~cm} /$ day $)$ and mycelium in line without confrontation with bacterium $(0.49 \pm 0.01 \mathrm{~cm} /$ day $)$. These results demonstrated that $R$. pickettii is capable of increasing the growth of $P$. eryngii mycelium and suggested that R. pickettii may produce compounds that improve mycelia growth.

In the current research, the capability of P. eryngii to degrade DDT was tested in PDB medium. Approximately $43 \%$ of the additional DDT vanished after the 7 -day incubation by P. eryngii culture (Table 1). DDT degradation by fungal-bacterial co-cultures was further examined by
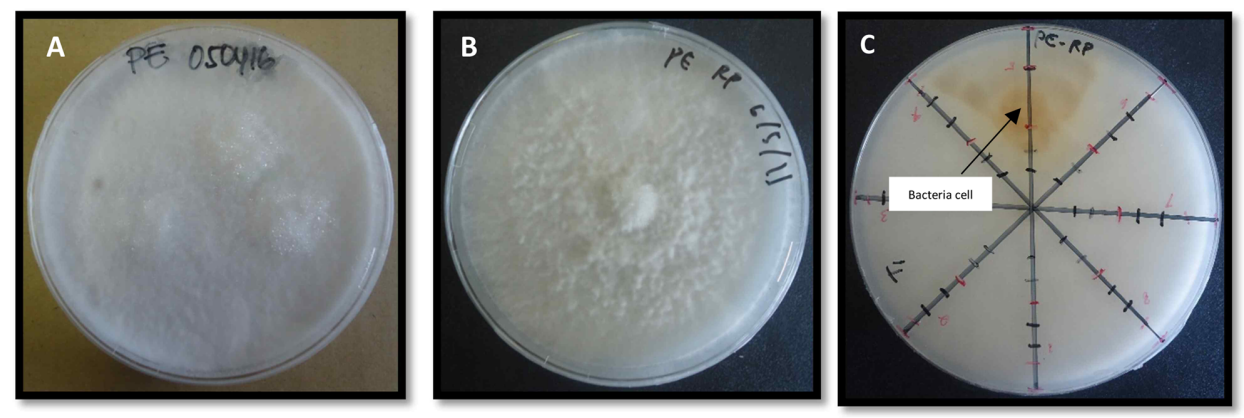

Fig. 1. Mycelium of P. eryngii after 12 days incubation (A) culture without bacteria (control), (B) co-cultures of P. eryngii and R. pickettii (front side), (C) co-cultures of P. eryngii and R. pickettii (back side). 
Table 1. Degradation of DDT by P. eryngii, R. pickettii and cocultures in PDB media after a 7-day incubation period.

\begin{tabular}{cccc}
\hline \multirow{2}{*}{$\begin{array}{c}\text { Amount of } \\
\text { bacterial } \\
\text { culture }(\mathrm{ml})\end{array}$} & \multicolumn{2}{c}{ DDT degradation (\%) } & Ratio of \\
\cline { 3 - 3 } & R. pickettii alone* & Co-cultures & optimization \\
\hline 0 & & $43.12 \pm 1.18^{\mathrm{a}}$ & \\
1 & $8.62 \pm 0.65^{\mathrm{a}}$ & $45.92 \pm 2.06^{\mathrm{a}}$ & $0.68^{\mathrm{a}}$ \\
3 & $12.08 \pm 0.88^{\mathrm{b}}$ & $48.80 \pm 2.07^{\mathrm{b}}$ & $0.88^{\mathrm{b}}$ \\
5 & $15.64 \pm 2.29^{\mathrm{b}}$ & $36.17 \pm 1.06^{\mathrm{b}}$ & $0.66^{\mathrm{a}}$ \\
7 & $30.87 \pm 0.52^{\mathrm{c}}$ & $78.23 \pm 0.60^{\mathrm{c}}$ & $1.06^{\mathrm{c}}$ \\
10 & $19.84 \pm 0.69^{\mathrm{b}}$ & $65.22 \pm 3.39^{\mathrm{b}}$ & $1.03^{\mathrm{c}}$ \\
\hline
\end{tabular}

The data were determined by HPLC. Data are presented as mean \pm standard deviations $(n=3)$. Data followed by the same lower case letter on each row are not significantly different $(p<0.05) ; 1 \mathrm{ml}$ R. pickettii $\approx 1.44 \times 10^{13}$ bacteria cells. *Setyo et al. (2018).

combining $P$. eryngii with $R$. pickettii. After $7 \mathrm{~d}$ of incubation, the co-cultures of $P$. eryngii with the addition of R. pickettii at $1,3,5,7$, and $10 \mathrm{ml}$ had degraded the DDT, with values of approximately $45.92 \pm 2.06,48.80 \pm 2.07$, $36.17 \pm 1.06,78.23 \pm 0.60$, and $65.22 \pm 3.39 \%$, respectively (Table 1). These results proved that adding bacterium extended the DDT degradation value by P. eryngii. Fig. 2 showed the similarity of DDT degradation rate by the particular fungus $P$. eryngii and bacterium $R$. pickettii, which compared with the co-cultures. The augmentation of $R$. pickettii in the culture of $P$. eryngii had a fluctuating reaction on the technique used during the degradation of DDT. DDT degradation by $P$. eryngii rose along with the increase of the addition of $R$. pickettii. The addition of $7 \mathrm{ml}$

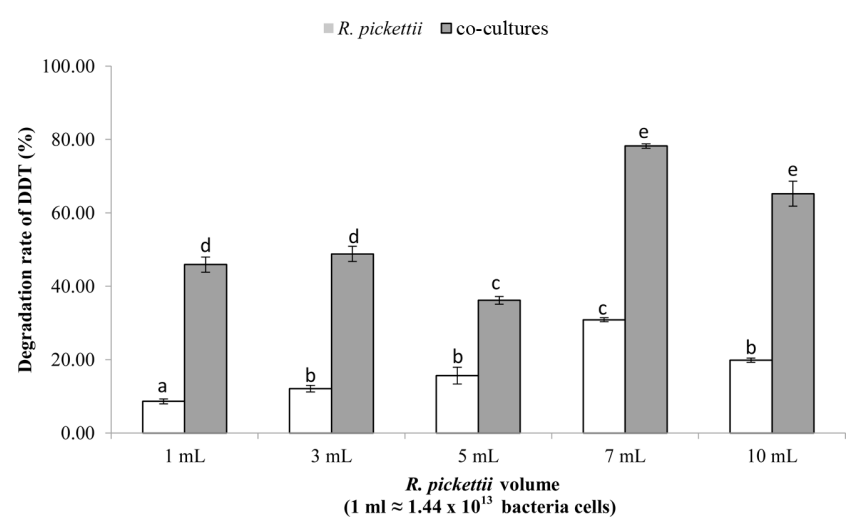

Fig. 2. Effect of addition of $R$. pickettii culture in the degradation of DDT by $P$. eryngii after a 7-day incubation period.

The R. pickettii only (white bars) and by co-cultures (gray bars). The data were determined by HPLC. Data are presented as mean and standard deviations $(n=3)$. The same lower case letter on each bar indicates no significant differences $(p<0.05)$. of $R$. pickettii concentration in cultured P. eryngii showed the highest degradation of about $78 \%$. The degradation rate of DDT by co-cultures was higher than the one caused by $R$. pickettii cultures only as well as P. eryngii only.

The effectiveness of co-cultures was determined by the ratio of optimization (RO). Co-cultures of $P$. eryngii and $7 \mathrm{ml} \mathrm{R}$. pickettii showed the best result among co-cultures by a ratio of 1.06 (Table 1 ). According to this result, the addition of R. pickettii culture at a $7 \mathrm{ml}$ was picked for additional experiments with time variation and identification of metabolic products.

The result of the time variation was determined, with time addition of $R$. pickettii being set at $0,1^{\text {st }}, 3^{\text {rd }}$, and $5^{\text {th }}$ day. The best times for adding bacteria into the fungal culture were at $0,1^{\text {st }}$, and $3^{\text {rd }}$ days of incubation with the DDT degradation being approximately $78 \%, 70 \%$, and $80 \%$, respectively. However, the augmentation of bacteria on the fifth day into the $P$. eryngii culture had the lowest DDT degradation of approximately $38 \%$.

Fig. 3 showed the metabolic products extracted from degrading DDT by co-cultures and its examination by GCMS. DDT was detected at the preservation time of $14.751 \mathrm{~min}$. The co-cultures of $P$. eryngii and $R$. pickettii resulted in DDE as a major metabolite, at retention time of 12.169 min and trace amounts of DDD and DDMU at the retention times of 13.245 and $11.327 \mathrm{~min}$, respectively. These kinds of metabolites were different from the metabolites produced by $P$. eryngii and $R$. pickettii only (data not shown). P. eryngii could transform DDT to DDE and DDMU, and R. pickettii could transform DDT to DDE as end products, which indicated that DDE was subjected to further transformation by $P$. eryngii. However, the degradation rate was dissimilar to the number of detected metabolic products (Table 2). The other metabolites might have been produced during the DDT degradation process, but could

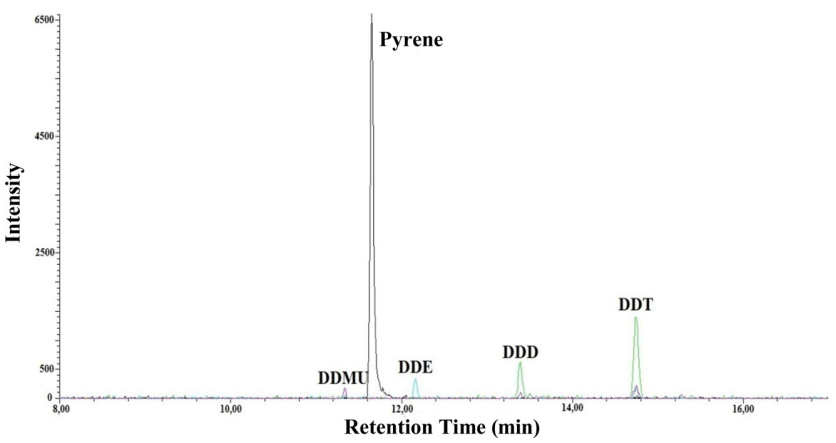

Fig. 3. GC/MS chromatogram of DDT degradation by cocultures of $P$. eryngii and $R$. pickettii. 
Table 2. Recovery and metabolic products by co-cultures of P. eryngii and R. pickettii.

\begin{tabular}{lccccc}
\hline \multirow{2}{*}{ Substrates } & $\begin{array}{c}\text { Degradation } \\
(\%)\end{array}$ & \multicolumn{4}{c}{ Metabolic Products Recovery (\%) } \\
\cline { 3 - 6 } & DDT & DDD & DDE & DDMU \\
\hline DDT & $78.23 \pm 0.06^{\mathrm{b}}$ & 18.46 & 17.75 & 4.83 & 1,48 \\
DDD & $45.99 \pm 3.46^{\mathrm{a}}$ & - & 45.71 & 7.15 & + \\
DDE & $75.37 \pm 0.84^{\mathrm{b}}$ & - & - & 21.33 & + \\
DDMU & $96.37 \pm 0.33^{\mathrm{c}}$ & - & - & - & 0.33 \\
\hline
\end{tabular}

The data were determined by HPLC. Data are presented as mean \pm standard deviations $(n=3)$. Data followed by the same lower case letter on each row are not significantly different $(p<0.05)$. "-“ not detected, "+" trace amount.

not be detected in the HPLC analysis. According to the HPLC analysis, DDD was the highest metabolite product in the culture, which means that it is the fundamental product of DDT degradation by P. eryngii and R. pickettii. DDD, DDE, and DDMU were also used to examine the degradation pathway. DDD, DDMU, and DDE were degraded by approximately $45 \%, 75 \%$, and $96 \%$, respectively. The DDD degradation by co-cultures resulted in DDE and DDMU as metabolic products and the DDD recovery was about $46 \%$. These results indicate that DDD was difficult to transform. DDE degradation by co-cultures resulted in DDMU as a metabolite product and DDE recovery of about $21 \%$.

\section{Discussion}

Mille-Lindblom and Tranvik [47] explained that different microorganisms could have positive interactions (synergistic), negative interactions (inhibition), and no interaction. According to the fungal-bacterial confrontation assay, $R$. pickettii had been potentially beneficial by enhancing the growth of $P$. eryngii and may have improved the ability of P. eryngii to degrade complex compounds. Hadibarata and Kristanti [48] reported that the increase in biomass production of $P$. eryngii could increase the enzyme production and simultaneously enhance the degradation of fluorine. The interaction between fungi and bacteria had been reported, some bacterial strains showed inhibitory or no effect on fungi growth and the other strains of bacteria could promote the growth of mycelium but the detailed mechanisms of improving mycelial growth and mycorrhizal formation by fungi remain unknown [25]. The communities of soil bacteria that have synergistic or negative interaction interact with fungi both physically, which increases mycelium growth and in the metabolic process, wherein the interaction produces secondary metabolites that are beneficial for fungi or other processes [49-52]. Commonly, there are several types of bacteria such as mycorrhiza helper bacteria (MHB) that significantly provide positive interactions with fungi. MHBs are a type of bacteria that is very dependent upon the strains that could increase the growth and survival rate of fungi, induce spore sprouting, provide nutrients for fungi and reduce the presence of pathogenic activities $[50,53,54]$. Ralstonia sp. is one of the MHB that could promote the hyphal growth of Suillus granulates [55]. However, there are no previous studies on the development of $P$. eryngii being promoted by $R$. pickettii. Additional research is needed to decipher the mechanism of R. pickettii that enhanced the growth of P. eryngii.

Regardless, P. eryngii has been proclaimed to possess the capability of degrading DDT in mineral medium [18]. In this study, P. eryngii degraded DDT about $43 \%$ in PDB medium during an incubation time of only $7 \mathrm{~d}$. Compared to preceding reports, DDT degradation capacity of P. eryngii in PDB medium is still low, but takes a short time (7d). However, considering the fact that the degradation rate was still low, P. eryngii was mixed with $R$. pickettii to enhance biodegradation. Since DDT was degraded in rich nutrient medium, there is a possibility of the dexterity of the ligninolytic enzymes in DDT degradation [15]. Even the laccase produced by $P$. eryngii had been reported to have the ability to remove toxic chemicals such as bisphenol-F (BPF), bisphenol-A (BPA), tetrabromobisphenol-A (TBBPA), and Nonylphenol (NP) [56]. In spite of that, aryl alcohol oxidase (AAO) has been isolated and characterized from P. eryngii and has similarity properties with Bjerkendra adusta and Phanerocheate chrysosporium [57], which may have a contribution to DDT degradation. AAO enzymes are capable to catalyze the oxidative dehydrogenation of unsaturated primary alcohols with hydrogen peroxide production [58] and also exhibit low activity on aromatic aldehydes [59]. However, the involvement of AAO as an isolated form of $P$. eryngii has never been reported yet. Thus, the P. eryngii enzyme involved in DDT degradation needs to be further examined.

In our previous works, $R$. pickettii (at concentration $7 \mathrm{ml}$ ) showed the highest degradation of DDT $30 \%$ (initial concentration $12.5 \mu \mathrm{M} / 20 \mathrm{ml}$ media) [35], which is much lower than the one by $P$. eryngii (Table 1). Since a characteristic of DDT is water insolubility, the biosurfactantproducing bacterium was used to degrade DDT. Previous reports described that the utilization of $R$. pickettii produces rhamnolipid as a biosurfactant [60]. How biosurfactants impact on DDT degradation at a variety of different sites depends on the concentration of R. pickettii. It has also been stated as having the capability to degrade a few persistent 
organic pollutants (POPs), such as BTEX [60], crude oil [61], and DDT [35]. There is a relation between the concentrations of bacteria and the level of DDT degradation, namely the higher concentration of bacteria, the higher the degradation rate obtained. However, excess bacterial concentration can reduce the DDT degradation level due to the increment of competition on nutrient requirements for bacterial growth, resulting in the bacteria producing toxic compounds as a priority for surviving [35]

A significant increment in the DDT degradation rate by P. eryngii was obtained after adding a biosurfactant that was produced by bacteria. The maximal DDT removal rate $(78 \%)$ was obtained in the co-cultures at the addition of $7 \mathrm{ml}$ (Fig. 2). The DDT degradation by co-cultures of fungi and bacteria has been reported previously. The synergistic co-cultures $P$. aeruginosa - P. ostreatus [17], P. brevispora B. subtilis [19], G. lingzhi - B. subtilis [21] were previously reported as having degradation efficiency of $75 \sim 86 \%$. In the cases of brown-rot fungus, Sariwati et al. [43] and Sariwati and Purnomo [44] reported that the addition of B. subtilis and $P$. aeruginosa increased DDT degradation by Fomitopsis pinicola, respectively. Recently, Setyo et al. [35] stated that the addition of $R$. pickettii to $D$. dickinsii culture enhanced the degradation of DDT from $54 \sim 69 \%$. In this study, $R$. pickettii showed a synergistic relationship with $P$. eryngii, although at the addition of $5 \mathrm{ml}$ of $R$. pickettii, the latter showed a decrease in the degradation of DDT. Overall, affixing R. pickettii into P. eryngii cultures showed an increased degradation of DDT. The addition of R. pickettii enhanced the degradation of DDT in co-cultures, and adding $7 \mathrm{ml}$ of $R$. pickettii cultures in cultured P. eryngii showed the highest degradation of approximately $78 \%$ and these outcomes illustrates that there is a synergistic relationship between $P$. eryngii and R. pickettii. R. pickettii had been known as a bacteria-producing biosurfactant, such as rhamnolipid [60]. Some studies found that rhamnolipid had the ability to decrease surface tension [63] so that the solubility of hydrophobic organic substances including DDT increased. A previous study also reported that with the aid of rhamnolipid as a biosurfactant, the degradation of pyrene by $P$. eryngii was accelerated with $93.6 \%$ removal after $30 \mathrm{~d}$ incubation [63]. However, different concentrations of $R$. pickettii culture resulted in different degradation rates of DDT by P. eryngii due to the increase in competition on nutrition needs. The concentration of biosurfactant resulting from $R$. pickettii and P. eryngii co-culture might produce some toxic metabolites for survival rather than for degrading DDT. To determine the effectiveness of various co-cultures, the ratio optimization (RO) was obtained by comparing the degradation of DDT in co-cultures and the total of that by particular fungi and bacteria $[43,44]$. RO $\geq 1$ indicated the synergistic mechanism between $P$. eryngii and $R$. pickettii to degrade DDT. In this research, $P$. eryngii with the addition of 7 and $10 \mathrm{ml}$ of $R$. pickettii showed synergistic mechanism with $\mathrm{RO}>1$, which indicated that $R$. pickettii enhances DDT degradation by $P$. eryngii because the DDT degradation rate by co-cultures was higher than the total of particular fungi and bacteria only. Thus, the addition of 1 , 3 , and $5 \mathrm{ml}$ of $R$. pickettii culture showed RO $<1$ (Table 1 ). From the obtained results, co-cultures of $P$. eryngii and $7 \mathrm{ml}$ of $R$. pickettii are the perfect co-cultures combination, with an RO of 1.06 (Table 2), and the highest level of DDT degradation. Therefore, it was chosen for further experiments on metabolite identification and variation of time.

The effect of bacteria inclusion into a P. eryngii culture on DDT degradation was also investigated. When bacteria were added at the fundamental stage of the degradation process (0 days), the topmost value of DDT degradation was retrieved, indicating the growth of $P$. eryngii enhanced by $R$. pickettii, followed by degradation process of DDT. R. pickettii GR4 inhibited the growth of $C$. herbarum, resulting in mild inhibition [64]. According to the confrontation assay in this research, it is already proved that R. pickettii has the ability to enhance $P$. eryngii mycelial growth (Fig. 1). The bacterial activities have been suggested to increase the growth of external mycelium of P. eryngii [65]. Furthermore, Ralstonia species grow slowly and require more than $50 \mathrm{~h}$ of incubation for visible colonies. Ralstonia species have one or more polar flagella in motile species and produce acid from glucose and several other carbohydrates [66]. The utilization of $P$. eryngii and its enzymes have been explored in degrading xenobiotics. Enzymes such as laccase and $\mathrm{MnP}$ remove toxic chemicals. Manganese is a vital part of the $\mathrm{MnP}$ catalytic cycle and an increase in its activity in the cultures is influenced by other factors. Research has it that organic acids affect the activities of $\mathrm{MnP}$, laccases and other degrading enzymes [56]. According to this result, it is suggested that the organic acid produced by R. pickettii could influence the activity of laccase and $\mathrm{MnP}$ that enhance the degradation of DDT. However, adding the bacteria after the fifth day of incubating, $P$. eryngii produced a reduced DDT degradation compared to those of the first and third day. This further implied that the 2-day cocultures of $P$. eryngii and R. pickettii was not sufficient to degrade DDT and proved that the ability of $P$. eryngii to degrade DDT is influenced by $R$. pickettii.

Some metabolites were detected by both HPLC and GCMS analysis. The metabolic products that were detected 
from $P$. eryngii culture only were DDE and DDMU, while from $R$. pickettii culture, DDE was the only one. Co-cultures of $P$. eryngii with the addition of $R$. pickettii $(7 \mathrm{ml})$ transformed DDT into some known metabolites such as DDE, DDD, and DDMU (Fig. 3). Additional investigation into the metabolite identification was carried out using the GC/MS analysis which indicated that there was no metabolites from DDMU and DDE degradation using cocultures of $P$. eryngii and $R$. pickettii $(7 \mathrm{ml})$. Fungi have been shown to acquire degradative abilities for DDT, in the current research. Subba-Rao and Alexander [67] stated that numerous species of fungi have the capability to convert DDT to some common metabolites, such as DDD, DDE, DDM, DBP, and DBH [14]. The degradation of DDT using white-rot fungi revealed that $P$. chrysosporium manifested by reductive dechlorination as well as hydroxylation of the ethane group to dicofol, DDD and 2,2-dichloro-1,1-bis(4chlorophenyl) ethanol (FW152). Presently, the metabolic process of DBP in fungi is unclear, despite the fact that the fungus Aspergillus niger converts DBP into 4-chlorobenzophenone through the reductive dechlorination of the aromatic ring [67]. Despite the fact that our study was unable to detect the formation of 4-chlorobenzophenone as a metabolite of DBP, the metabolism of 4-chlorobenzophenone was not excluded. According to the identification of metabolic products, it is suggested that the first step of DDT degradation by co-cultures is most likely reductive dechlorination to DDD and consists of a single electron transfer, transformation of an alkyl radical and removal of a chloride ion [68-70]. Experiments performed with DDD as substrate demonstrated that transformation of DDD into DDE by dehydrochlorination, followed a concerted mechanism in two proton transfers, the $\mathrm{C}_{2}-\mathrm{Cl}_{2}$ bond cleavage, and double bond formation of $C_{1}-C_{2}[51,71]$, affected by the distribution of the chlorine atoms [72]. The latter metabolite was then further degraded to DDMU. Fig. 3 illustrates that DDD residues were higher, which means that its degradation was less than that of DDE or DDT due to its strong bonds [73, 74].

According to the identification of metabolites, P. eryngii could transform DDT to DDE and DDMU as metabolic products. $R$. pickettii could transform DDT to DDE as a metabolic product via elimination of chloride ion [24, 75]. Co-cultures of P. eryngii and R. pickettii transform DDT to DDD via reductive dechlorination, followed by dehydrochlorination to DDE. DDE then underwent dechlorination to DDMU, thereby showing that DDMU was subjected to further transformation by P. eryngii and DDD transformed by co-cultures. In this study, the DDT degradation<smiles>Clc1ccc(C(c2ccc(Cl)cc2)C(Cl)(Cl)Cl)cc1</smiles><smiles>C=C=C</smiles>

DDT<smiles>C=C=C</smiles><smiles>ClC(Cl)=C(c1ccc(Cl)cc1)c1ccc(Br)cc1</smiles><smiles>Cl/C=C\c1ccc(Cl)cc1</smiles>

Fig. 4. Proposed DDT degradation pathway by co-cultures of $P$. eryngii and R. pickettii as well as by particular R. pickettii and $P$. eryngii. P. eryngii only (thin black arrows), R. pickettii only (dotted arrows), co-cultures (open arrows).

pathway in co-cultures of $P$. eryngii and $R$. pickettii is proposed as shown in Fig. 4. This pathway varies from those projected during the retraction of DDE to DDD. Furthermore, DDD, dichlorobenzophenone and FW-152 were produced in DDT degradation by $P$. chrysosporium $[14,67]$, and co-cultures of F.pinicola and B. subtilis emerged into a combination of metabolites of DDE, DDD, and DDMU [43]. DDT was transformed into DDD through the reductive dechlorination process, then dehydrogenated into DDE and followed by the dechlorination process which transformed it to DDMU. This degradation pathway resembled the degradation pathway by Gram-negative bacteria, as reported by Masse et al. [75].

In this research, the abilities of bacterium $R$. pickettii to enhance DDT biodegradation by white-rot fungus P. eryngii was investigated. DDT was degraded by P. eryngii culture by only about $43.12 \pm 1.18 \%$. However, the addition of $7 \mathrm{ml}$ of $R$. pickettii culture into P. eryngii culture could increase the biodegradation of DDT to about $78.23 \pm 0.6 \%$ during 7 days of incubation. DDD, DDE, and DDMU were detected as the metabolites of DDT degradation by the co-cultures. The DDT was transformed into DDD via dechlorination, followed by the formation of DDE through dehydrogenation, 
and then the formation of DDMU via dehydrochlorination. This indicated that the addition of $R$. pickettii has a synergistic role in enhancing the biodegradation of DDT by P. eryngii.

\section{Acknowledgments}

This research was backed by a grant from the Institut Teknologi Sepuluh Nopember, Indonesia (No. 653/PKS/ ITS/2018).

\section{Conflict of Interest}

The authors have no financial conflicts of interest to declare.

\section{References}

1. Sudaryanto A, Takahashi S, Tanabe S. 2007. Persistent toxic substances in the environment of Indonesia. Dev. Environ. Sci. 7: 587-627.

2. Kinuthia M, Hamadi IB, Anne WM, Ciira K, Muniru KT. 2010. Degradation of dichlorodiphenyltrichloroethane (DDT) by bacterial isolates from cultivated and uncultivated soil. Afr. J. Microbiol. Res. 4: 185-196.

3. Tsakiris IN, Goumenou G, Tzatzarakis MN, Alegakis AK, Tsitsimpikou C, Ozcagli E, et al . 2015. Risk assessment for children exposed to DDT residues in various milk types from the Greek market. Food Chem. Toxicol. 75: 156-165.

4. Chu W. 1999. Photodechlorination mechanism of DDT in a UV/Surfactant system. Environ. Sci. Technol. 33: 421-425.

5. Matsunaga A, Yasuhara A. 2005. Dechlorination of polychlorinated organic compounds by electrochemical reduction with naphthalene radical anion as mediator. Chemosphere 59: 1487-1496.

6. Sayles GD, You GR, Wang MX, Kuperferle MJ. 1997. DDT, DDD and DDE Dechlorination by zero-valent iron. Environ. Sci. Technol. 31: 3448-3454.

7. Kamei I, Suhara H, Kondo R. 2005. Phylogenetical approach to isolation of white-rot fungi capable of degrading polychlorinated dibenzo-p-dioxin. Appl. Microbiol. Biotechnol. 69: 358-366.

8. Kamei I, Sonoki S, Haraguchi K, Kondo R. 2006. Fungal bioconversion of toxic polychlorinated biphenyls by whiterot fungus, Phlebia brevispora. Appl. Microbiol. Biotechnol. 73: 932-940.

9. Kamei I, Takagi K, Kondo R. 2011. Degradation of endosulfan and endosulfan sulfate by white-rot fungus Trametes hirsute. J. Wood Sci. 57: 317-322.

10. Aust SD. 1990. Degradation of Environmental pollutants by Phanerochaete chrysosporium. Microbiol. Ecol. 20: 197-209.
11. Pointing SB. 2001. Feasibility of bioremediation by white rot fungi. Appl. Microbiol. Biotechnol. 57: 20-33.

12. Reddy CA. 1995. The potential for white rot fungi in the treatment of pollutants. Curr. Opin. Biotechnol. 6: 320-328.

13. Reddy CA, Mathew Z. 2001. Bioremediation potential of white rot fungi. pp. 52-78. In Gadd GM (ed.), Fungi in bioremediation. Cambridge University Press, London.

14. Bumpus JA, Aust SD. 1987. Biodegradation of DDT [1,1,1trichloro-2,2-bis(4-chlorophenyl) ethane] by the white rot fungus Phanerochaete chrysosporium. Appl. Environ. Microbiol. 53: 2011-2008.

15. Purnomo AS, Mori T, Kamei I, Nishii T, Kondo R. 2010. Application of mushroom waste medium from Pleurotus ostreatus for bioremediation of DDT contaminated soil. Int. Biodet. Biodeg. 64: 397-402.

16. Purnomo AS, Mori T, Kamei I, Kondo R. 2011. Basic studies and applications on bioremediation of DDT: A review. Int. Biodet. Biodeg. 65: 921-930.

17. Purnomo AS, Ashari K, Hermansyah F. 2017. Evaluation of the synergistic effect of mixed cultures of white-rot fungus Pleurotus ostreatus and biosurfactant-producing bacteria on DDT biodegradation. J. Microbiol. Biotechnol. 27: 1306-1315.

18. Arisoy M. 1998. Biodegradation of chlorinated organic compounds by white-rot fungi. Bull. Environ. Contam. Toxicol. 60: 872-876.

19. Purnomo AS, Fajriah 2017. Pengaruh penambahan Bacillus subtilis pada biodegradasi DDT Oleh Phlebia brevispora. Akta Kim. Indones. 2: 58-65.

20. Xiao P, Mori T, Kamei I, Kondo R. 2011. A novel metabolic pathway for biodegradation of DDT by the white rot fungi, Phlebia lindtneri and Phlebia brevispora. Biodegradation 22: 859867.

21. Grizca BE, Setyo PA. 2018. Abilities of co-cultures of whiterot fungus Ganoderma lingzhi and bacteria Bacillus subtilis on Biodegradation DDT. J. Physics Conf. Series 1095: 102015.

22. Purnomo AS, Kamei I, Kondo R. 2008. Degradation of 1,1,1trichloro-2,2-bis(4-chlorophenyl) ethane) (DDT) by brownrot fungi. J. Biosci. Bioeng. 105: 614-621.

23. Purnomo AS, Mori T, Kondo R. 2010. Involvement of fenton reaction in DDT degradation by brown rot fungi. Int. Biodeterior. Biodegradation 64: 560-565.

24. Purnomo AS, Mori T, Takagi K, Kondo R. 2011. Bioremediation of DDT contaminated soil using brown-rot fungi. Int. Biodeterior. Biodegradation 65: 691-695.

25. Kamei I, Yoshida T, Enami D, Meguro S. 2012. Coexisting Curtobacterium bacterium promotes growth of white-rot fungus Stereum sp. Curr. Microbiol. 64: 173-178.

26. Clausen CA. 1996. Bacterial association with decaying wood: A review. Int. Biodeterior. Biodegradation. 37: 101-107.

27. Kukor JJ, Olsen RH. 1992. Genetic organization and regulation of a meta cleavage pathway for catechols produced from catabolism of toluene, benzene, phenol, and cresols by Pseudomonas pickettii PK01. J. Bacteriol. 174: 6518-6526. 
28. Massol-Deya A, Weller R, Rios-Hernandez L, Zhou JZ, Hickey RF, Tiedje JM. 1997. Succession and convergence of biofilm communities in fixed-film reactors aromatic hydrocarbons in groundwater. Appl. Environ. Microbiol. 63: 270-27.

29. Ryan MP, Pembroke JT, Adles C. 2007. Ralstonia pickettii in environmental biotechnology: potential and applications. J. Appl. Microbiol. 103: 754-64.

30. McClay K, Fox BG, Steffan RJ. 1996. Chloroform mineralization by toluene oxidizing bacteria. Appl. Environ. Microbiol. 62: 2716-2722.

31. Kiyohara H, Hatta T, Ogawa Y, Kakuda T, Yokoyama H, Takizawa N. 1992. Isolation of Pseudomonas pickettii strains that degrade 2,4,6-trichlorophenol and their dechlorination of chlorophenols. Appl. Environ. Microbiol. 58: 1276-1283.

32. Yabannavar AV, Zylstra GJ. 1995. Cloning and characterization of the fenes for p-nitrobenzoate degradation from Pseudomonas pickettii YH105. Appl. Environ. Microbiol. 61: 4284-4290.

33. Sharma OP, Dawra RK, Datta AK, Kanwar SS. 1997. Biodegradation of Lantadene A, The Pentacyclic Triterpenoid Hepatotoxin by Pseudomonas pickettii. Lett. Appl. Microbiol. 24: 229-232.

34. Kahng HY, Byrne AM, Olsen RH, Kukor JJ. 2000. Characterization and Role of tbuX in Utilization of Toluene by Ralstonia pickettii PKO1. J. Bacteriol. 182: 1232-1242.

35. Setyo PA, Dwi RH, Sri F, Sulistyo PH, Ichiro K. 2018. Effects of bacterium Ralstonia pickettii addition on DDT biodegradation by Daedalea dickinsii. Res. J. Chem. Environ. 22(Special issue II): 151-156.

36. Purnomo AS. 2017. Microbe-assisted degradation of aldrin and dieldrin. In Singh SN (ed.), Microbe-Induced Degradation of Pesticides, pp. 1-22. 1st edn. Springer Nature, Switzerland.

37. Purnomo AS, Nawfa R, Martak F, Shimizu K, Kamei I. 2017. Biodegradation of aldrin and dieldrin by the white-rot fungus Pleurotus ostreatus. Curr. Microbiol. 74: 320-324.

38. Rizqi HD, Purnomo AS. 2017. The ability of brown-rot fungus Daedalea dickinsii to decolorize and transform methylene blue dye. World J. Microbiol. Biotechnol. 33: 92.

39. Purnomo AS, Koyama F, Mori T, Kondo R. 2010. DDT degradation potential of cattle manure compost. Chemosphere 80: 619-624.

40. Purnomo AS, Mori T, Putra SR, Kondo R. 2013. Biotransformation of heptachlor and heptachlor epoxide by white-rot fungus Pleurotus ostreatus. Int. Biodeterior. Biodegradation 82: 40-44.

41. Wahyuni S, Suhartono MT, Khaeruni A, Purnomo AS, Asranudin, Holilah, et al. 2016. Purification and characterization of thermostable chitinase from Bacillus SW41 for chitin oligomer production. Asian J. Chem. 28: 2731-2736.

42. Wahyuni S, Khaeruni A, Purnomo AS, Asranudin, Holilah, Fatahu 2017. Characterization of mannanase isolated from corncob waste bacteria. Asian J. Chem. 29: 1119-1120.
43. Sariwati A, Purnomo, AS, Kamei I. 2017. Abilities of cocultures of brown-rot fungus Fomitopsis pinicola and Bacillus subtilis on biodegradation DDT. Curr. Microbiol. 74: 1068-1069.

44. Sariwati A, and Purnomo, AS. 2018. The effect of Pseudomonas aeruginosa addition on 1,1,1 Trichloro 2,2 bis (4 chlorophenyl) ethane DDT biodegradation by brown-rot fungus Fomitopsis pinicola. Indon. J. Chem. 18: 75-81.

45. Purnomo AS, Putra SR, Shimizu K, Kondo R. 2014. Biodegradation of heptachlor and heptachlor epoxidecontaminated soils by white-rot fungal inocula. Environ. Sci. Pollut. Res. 21: 11305-11312.

46. Kamei I. 2017. Co-culturing effects by coexisting bacteria on wood degradation by Trametes versicolor. Curr. Microbiol. 74: 125-131.

47. Mille-Lindblom C, Tranvik L. 2003. Antagonism between bacteria and fungi on decomposing aquatic plant litter. Microbiol. Ecol. 45: 73-182.

48. Hadibarata T, Kristanti RA. 2014. Potential of a white-rot fungus Pleurotus eryngii F032 for degradation and transformation of fluorine. Fungal Biol. 118: 222-227.

49. Bonfante P, Anca IA. 2009. Plants, mycorrhizal fungi, and bacteria: a network of interactions. Annu. Rev. Microbiol. 63: 363-383.

50. Frey-Klett P, Garbaye J, Tarkka M. 2007. The mycorrhiza helper bacteria revisited. New Phytol. 176: 22-36.

51. Manna RN, Dybala-Defratyka A. 2013. Insights into the elimination mechanisms employed for the degradation of different hexachlorocyclohexane isomers using kinetic isotope effects and docking studies. J. Phys. Org. Chem. 26: 797-804.

52. Ramadhania NR, Purnomo AS, Fatmawati S. 2018. Antibacterial activities of Syzygium polyanthum wight leaves. AIP Conf. Proc. 2049: 020024.

53. Ramadhania NR, Harun F, Purnomo AS, Fatmawati S. 2019. Anti-oxidant and anti-bacterial activities of Anthurium plowmanii leaves extracts. Mal. J. Fund. Appl. Sci. 15: 194-199.

54. Johansson J, Paul LR, Finlay RD. 2004. Microbial interactions in the mycorrhizosphere and their significance for sustainable agriculture. FEMS Microbiol. Ecol. 48: 1-13.

55. Kataoka R, Futai K. 2009. A new mycorrhizal helper bacterium, ralstonia species, in the ectomycorrhizal symbiosis between Pinus thunbergii and Suillus granulatus. Biol. Fertil. Soils 45: 315-320.

56. Chang BV, Chang YM. 2016. Biodegradation of toxic chemicals by Pleurotus eryngii in submerged fermentation and solid-state fermentation. J. Microbiol. Immunol. Infect. 49: 175-181.

57. Varela E, Guillen F, Martinez AT, Martinez MJ. 2001. Expression of Pleurotus eryngii aryl-alcohol oxidase in Aspergillus nidulans: purification and characterization of the recombinant enzyme. Biochim. Biophys. Acta (BBA) - Protein Struc. Mol. Enzymol. 1546: 107-113.

58. Guillén F, Martínez AT, Martínez MJ, Evans CS. 1994. Hydrogen-peroxide-producing system of Pleurotus eryngii 
involving the extracellular enzyme aryl-alcohol oxidase. Appl. Microbiol. Biotechnol. 41: 465-470.

59. Ferreira P, Medina M, Guillén F, Martínez MJ, Van Berkel WJH, Martínez AT. 2005. Spectral and catalytic properties of aryl-alcohol oxidase, a fungal flavoenzyme acting on polyunsaturated alcohols. Biochem. J. 389: 731-738.

60. Plaza GA, Wypych J, Berry C, Brigmon RL. 2007. Utilization of monocyclic aromatic hydrocarbons individually and in mixture by bacteria isolated from petroleum-contaminated soil. World J. Microbiol. Biotechnol. 23: 533-542.

61. Płaza GA, Łukasik K, Wypych J, Jawecki N, Berry C, Brigmo RL. 2008. Biodegradation of crude oil and distillation products by biosurfactant-producing bacteria. Pol. J. Environ. Stud. 17: 87-94.

62. Abalos A, Pinazo A, Infante MR, Casals M, Garcia F, Manresa A. 2001. Physicochemical and antimicrobial properties of new rhamnolipids produced by Pseudomonas aeruginosa AT10 from soybean oil refinery wastes. Langmuir 17: $1367-1371$

63. Teh ZC, Hadibarata T. 2014. Enhanced degradation of pyrene and metabolite identification by Pleurotus eryngii F032. Water Air Soil Pollut. 225: 1909.

64. Baschien C, Rode G, Böckelmann U, Götz P, Szewzyk U. 2009. Interactions between hyphosphere-associated bacteria and the Fungus Cladosporium herbarum on aquatic leaf litter. Microbiol. Ecol. 58: 642-650.

65. Green H, Larsen J, Olsson PA, Jensen DF, Jakobsen I. 1999. Suppression of the biocontrol agent Trichoderma harzianum by mycelium of the arbuscular mycorrhizal fungus Glomus intraradices in root-free soil. Appl. Microbiol. Biotechnol. 65: $1428-1434$.

66. Steinberg JP, Burd EM. 2005. Mandell, Douglas, and Bennets Principle and Practice of Infectious Diseases. $8^{\text {th }}$ Edition. Elsevier Inc: Philadelphia.
67. Subba-Rao RV, Alexander M. 1985. Bacterial and fungal cometabolism of 1,1,1-trichloro-2,2-bis(4-chlorophenyl) ethane (DDT) and its breakdown products. Appl. Environ. Microbiol. 49: 509-516.

68. Baxter GJ, Graham AB, Lawrence JR, Wiles J, Peterson JR. 2001. Salicylic acids in soups prepared from organically and non-organically grown vegetables. Eur. J. Nutr. 40: 289-292.

69. Foght J, April T, Biggar K, Aisalbie J. 2010. Bioremediation of DDT-contaminated soils: a review. Bioremiat. J. 5: 225-246.

70. Laili K, Fatati N, Inneke PF, Setyo PA, Mardi S, Taslim E, et al. 2018. In vitro antioxidant activity of Sonneratia ovata backer extract. Res. J. Chem. Environ. 22(Special issue II): 146-150.

71. Brittain DRB, Pandey R, Kumari K, Sharma P, Pandey G, Lal R, et al. 2011. Competing SN2 and E2 reaction pathways for hexachlorocyclohexane degradation in the gas phase, solution and enzymes. Chem. Commun. 47: 976-978.

72. Halasa AF, Massie JM, Ceresa RJ. 2005. The Chemical Modification of Polymers. pp. 497-528. In: Science and Technology of Rubber (Third Edition). Academic Press, New York.

73. Zhao Y, Yi X, Li M, Liu L, Ma W. 2010. Biodegradation kinetics of DDT in soil under different environmental conditions by laccase extract from white rot fungi. Chinese J. Chem. Eng. 18: 486-492.

74. Zhao YC, Yi XY, Zhang M, Liu L, Ma WJ. 2010. Fundamental study of degradation of dichlorodiphenyltrichloroethane in soil by laccase from white rot fungi. Int. J. Environ. Sci. Technol. 7: 359-366.

75. Massé R, Lalanne D, Messier F, Sylvestre M. 1989. Characterization of new bacterial transformation products of 1,1,1-trichloro-2,2-bis-(4-chlorophenyl) ethane (DDT) by gas chromatography/mass spectrometry. J. Mass Spectrom. 18: 741-752. 